\title{
Detection of Quantitative Trait Loci and Inheritance of Root-knot Nematode Resistance in Sweetpotato
}

\author{
Jim C. Cervantes-Flores, G. Craig Yencho, Kenneth V. Pecota, and Bryon Sosinski ${ }^{1}$ \\ Department of Horticultural Science, North Carolina State University, Campus Box 7609, Raleigh, \\ NC 27695 \\ Robert O.M. Mwanga
Namulonge Agricultural and Animal Production Research Institute, P.O. Box 7084, Kampala,
Uganda
}

AdDitional INDEX WoRDs. Ipomoea batatas, Meloidogyne incognita, RKN, quantitative trait loci

\begin{abstract}
Resistance to root-knot nematodes [Meloidogyne incognita (Kofoid \& White) Chitwood] in sweetpotato [Ipomoea batatas (L.) Lam.] was studied in a mapping population consisting of 240 progeny derived from a cross between 'Beauregard', the predominant cultivar in the United States, and 'Tanzania', an African landrace. Quantitative trait loci (QTL) analyses to locate markers associated with resistance to root-knot nematodes (RKN) were performed using genetic maps based on parental segregation in 'Beauregard' and 'Tanzania' consisting of 726 and 947 single-dose amplified fragment length polymorphism (AFLP) markers, respectively. RKN resistance in the progeny was highly skewed with most of the progeny exhibiting medium to high levels of resistance. Single-point analysis of variance and interval mapping revealed seven consistently significant QTL in 'Tanzania' and two significant QTL in 'Beauregard'. In 'Tanzania', three QTL were associated with reduction in resistance as measured by the number of RKN egg masses and explained $\approx 20 \%$ of the variation. Another four QTL had positive effects on resistance and explained $\approx 21 \%$ of the variation. Other minor QTL explained $\approx 2 \%$ or less of the variation but were not always consistent across geographical locations. In 'Beauregard', two QTL had positive effects on RKN resistance and explained $\approx 6 \%$ of the observed variation. Based on molecular and phenotypic data, RKN resistance in sweetpotato is hypothesized to be conferred by several genes, but at least nine AFLP markers (seven from 'Tanzania' and two from 'Beauregard') are associated with genomic regions that have the biggest effect in the number of egg masses of RKN produced in the root system.
\end{abstract}

Root-knot nematodes are widespread worldwide and cause significant reductions in the yield and quality of storage roots in sweetpotato (Clark and Moyer, 1988). The worldwide distribution of root-knot nematodes (RKN), Meloidogyne Goeldi species, their extensive host ranges, and associations with fungi and bacteria in disease complexes rank RKN among the major pathogens affecting crops (Sasser, 1980). Greater than 50 species of RKN have been described, but Meloidogyne incognita, M. javanica (Treub) Chitwood, M. arenaria (Neal) Chitwood, and M. hapla Chitwood account for more than 95\% of the species detected in agricultural soils worldwide (Sasser and Carter, 1985; Taylor et al., 1982). The average damage to field crops by plant-parasitic nematodes is estimated at $10 \%$ worldwide (Whitehead, 1998). However, paradoxically much of the damage caused by RKN goes undetected.

The characteristic symptoms of RKN damage to sweetpotato are round to spindle-shaped swellings (galls) on fibrous roots and cracks on fleshy storage roots (Lawrence et al., 1986). Nematode injury inflicted during early root development often predisposes storage roots to the formation of cracks in the

Received for publication 15 May 2008. Accepted for publication 7 Oct. 2008 This paper is a portion of a dissertation submitted by Jim C. Cervantes-Flores. The research reported in this publication was supported by funding provided by the McKnight Foundation Collaborative Crops Research Project, the North Carolina Sweetpotato Commission, Inc., the Consortium for Plant Biotechnology Research, and the GoldenLEAF Foundation.

We thank Dr. Zhao-Bang Zeng for his valuable discussion and Cindy Pierce, Jennifer Swift, Amanda Kroll, and Christina Rowe for their assistance in the greenhouse and laboratory.

${ }^{1}$ Corresponding author. E-mail: bryon_sosinski@ncsu.edu. cortex (Thomas and Clark, 1983) and these cracks provide sites for invasion of secondary and/or pathogenic organisms. These cracks subsequently lead to rotting of the storage roots (Jatala, 1991). Although nematocides provide a fairly effective means of control of RKN, they are very expensive and highly neurotoxic. The preferable, more economic, and most sustainable method of nematode control is through host resistance, and a number of resistant sweetpotato clones are available (Cervantes-Flores et al., 2002a; Lawrence et al., 1986). However, the most predominant cultivar grown in the United States, Beauregard, is very susceptible to M. incognita and M. javanica (Cervantes-Flores et al., 2002b).

Resistance to RKN in sweetpotato is not well understood. Both qualitative (Ukoskit et al., 1997) and quantitative (Cordner et al., 1954; Giamalva et al., 1961; Jones and Dukes, 1980; Struble et al., 1966) types of inheritance have been suggested. It has also been suggested that independent sources of resistance were responsible for the differences observed in the inheritance of resistance in sweetpotato to different RKN (Jones and Dukes, 1980) and that resistance in different sweetpotato genotypes may have multiple origins (Mcharo et al., 2005a). Similarly, studies of resistance to several species and populations of Meloidogyne sp. in sweepotato have shown that several genes may be involved in the inheritance to $\mathrm{RKN}$ in sweetpotato and that resistance to different RKN species may be conferred by different genes (Cervantes-Flores et al., 2002b; Sano et al., 2002). Histological studies have shown that juvenile (J2 stage) RKN penetrate both susceptible and resistant sweetpotato genotypes as well as other Ipomoea L. species, including I. trifida (Kunth) Don (Komiyama et al., 2006). However, in 
susceptible genotypes, the nematodes become established, whereas in resistant genotypes, necrotic reactions prevent further pathogen development. These observations were similar to the resistance reaction observed earlier in other species against nematode infection (Dropkin, 1969a, 1969b; Paulson and Webster, 1972).

Molecular markers have been used successfully in many crops for locating and cloning candidate genes associated with resistance to different pathogens (Barr et al., 1998; Cregan et al., 1999; Dirlewanger et al., 1994; Gebhardt and Valkonen, 2001; Lagudah et al., 1997; Tao et al., 2000; Wang et al., 1994, 2001). Relatively few DNA marker-based genetic studies of economically important traits have been conducted in sweetpotato to date (Mcharo et al., 2005a, 2005b; Mwanga et al., 2002; Ukoskit et al., 1997). In studying resistance to RKN, Ukoskit et al. (1997) identified a single random amplified polymorphic DNA marker $\left(\mathrm{OP} 15_{1500}\right)$ linked to RKN resistance in a cross between a resistant ('Regal') and a susceptible ('Vardaman') sweetpotato. However, the linkage was not very strong. Mcharo et al. (2005a) applied discriminant analysis to study RKN resistance in two unrelated sweetpotato populations and identified some associations with RKN resistance. However, as a result of the small population size and number of markers used in their study, an overestimation of the effect of the analyzed markers may have occurred. The importance of population size to detect quantitative trait loci (QTL) has been strongly emphasized by many researchers (Collard et al., 2005; Doerge et al., 1997; Ripol et al., 1999; Tanksley, 1993). In a polyploid crop such as sweetpotato, a large population size is critical to observe a representative sample of recombination. Therefore, the larger the population size, the higher the statistical power and the most likely significant QTL with minor effects can be detected (Collard et al., 2005).

In this study, we describe the identification of amplified fragment length polymorphism (AFLP) markers associated with RKN resistance through a QTL mapping study performed on a large mapping population derived from a wide cross between sweetpotato cultivars Tanzania and Beauregard. One of the parental lines 'Tanzania', an African landrace, demonstrated broad and strong resistance to four major RKN species (Cervantes-Flores et al., 2002b), whereas 'Beauregard' is highly susceptible to RKN infection. This research increases our understanding of RKN resistance in sweetpotato through the localization of QTL associated with resistance in saturated molecular maps. This work may also open the door for positional cloning and/or the implementation of marker-assisted selection breeding in sweetpotato for RKN resistance.

\section{Materials and Methods}

Mapping Population. A mapping population of 240 progeny derived from the cross 'Tanzania' (female) $\times$ 'Beauregard' (male) sweetpotato was used for this study. Both parents differ significantly in their resistance reaction to RKN with 'Tanzania' containing high levels of resistance to several RKN species and 'Beauregard' being very susceptible (Cervantes-Flores et al., 2002a, 2002b). The population development has been described in detail by Cervantes-Flores et al. (2008). The entire mapping population was individually maintained in $20.3-\mathrm{cm}$ diameter pots containing Fafard P4 soil mix (Fafard, Agawam, $\mathrm{MA}$ ) in the greenhouse. For each progeny, six three-node cuttings were taken and planted into 72-cell Landmark ${ }^{\mathrm{TM}}$ seedling trays (Stuewe \& Sons, Corvallis, OR) containing Fafard P4 for their clonal propagation in the greenhouse. Plants were grown under greenhouse conditions of 25 to $28^{\circ} \mathrm{C}$ and watered as needed.

ROOT-KNOT NEMATODE SCREENING. The resistance reaction was assessed by the number of egg masses (EM) present in the root system. To do this, four $15-\mathrm{cm}$ long cuttings from each genotype were transplanted into $150-\mathrm{cm}^{3}$ model SC-10 Super Cell Conetainers ${ }^{\mathrm{TM}}$ (Stuewe \& Sons) containing a 3:1 pasteurized mix (by volume) of coarse sand and field soil (loamy sand: $88.9 \%, 8.3 \%$ silt, and 2.8\% clay), respectively (CervantesFlores et al., 2002a, 2002b). The experiment was arranged in a completely randomized design with four replications in two different tests.

Root-knot nematodes, $M$. incognita (race 3, the most predominant in North Carolina), were cultured on 'Rutgers' tomato plants (Solanum lycopersicum L.). Eggs were extracted using the $\mathrm{NaOCl}$ method described by Hussey and Barker (1973), and $\approx 10,000$ eggs were injected into the soil to infest each individual. The inoculations were applied 2 weeks after planting to each cutting. Plants were grown under greenhouse conditions of 25 to $28{ }^{\circ} \mathrm{C}$ and watered as needed.

Plants were harvested at $56 \mathrm{~d}$ after inoculation and rated by counting the EM number present on the root system for each genotype (Cervantes-Flores et al., 2002b). The visual rating was done after staining the root tissue with red food coloring (McCormick and Co., Baltimore, MD) for $\approx 30 \mathrm{~min}$. In our laboratory, red food coloring is used to replace Phloxine B, which is highly toxic, to stain the EM and allows a clear visualization of the galls on the roots. Results from this method are comparable to those described by Hussey and Barker (1973), and there is the added benefit of nontoxicity. The counts of EM per root system were standardized by logarithmic transformation $[\log (\mathrm{x})]$ and analysis of variance (ANOVA) using SAS (version 9.1; SAS Institute, Cary, NC) was conducted to assess if there were any significant differences between tests. Data were then averaged over the four replications in each test to simplify further analysis.

Genotyping. The development of the genetic map of 'Tanzania' $\times$ 'Beauregard' was described by Cervantes-Flores et al. (2008). Briefly, the parental maps consisted of 726 and 947 single-dose AFLP markers ordered into 90 and 86 linkage groups, respectively, for 'Beauregard' and 'Tanzania'.

Statistical analysis. Given the number of replications and nature of the experiment, RKN resistance data values were averaged across replications within each test. For analysis, data were treated as $\mathrm{BC}_{2} \mathrm{~F}_{1}\left(\mathrm{~F}_{1}\right.$ backcrossed to $\left.\mathrm{P}_{2}\right)$, because the analysis was performed only on the single-dose marker framework maps. Single-point QTL analysis was performed using WinQTL Cartographer (Wang et al., 2005) to determine any association between the AFLP markers and the trait. Interval mapping (Lander and Botstein, 1989) and composite interval mapping analysis was also performed to determine QTL confidence interval using standard algorithms implemented in WinQTL. Significance of the QTL was established by their respective logarithm of the odds (LOD) score or their likelihood ratio (LR) as calculated by interval and composite interval mapping analysis. A locus was considered significant if its LOD or LR was higher than their respective threshold value (threshold values were calculated automatically by WinQTL according to the variation of the particular trait data; typical threshold values are $L O D=2.5$ 
and LR $=11.5)$. Additionally, to overcome limitations of mapping procedures, we have performed single-point analysis on all of the markers disregarding their segregation ratios and relation to each other using PROC CORR in SAS (Version 9.1). On location of markers with a significant effect, results of the analysis were further analyzed using PROC GLM in SAS (Version 9.1) for interactions (alpha $=0.05$ ) that could help explain the observed variation. Also, to assess if there were any other interactions with other markers from the map, that initially may have shown no significance by themselves, an iterative analysis using PROC GLM was conducted. Potential interactions were considered significant and were further analyzed if $P<0.05$. Significant QTL ( 1 -LOD confidence interval) were graphically represented in the linkage groups by rectangular bars spreading through the markers associated to the variation of the trait using MapChart (Voorrips 2002). Additionally, broad-sense heritability of RKN resistance was calculated based on the entry means over the replications per test for each genotype (Nyquist, 1991).

\section{Results}

When analyzed by ANOVA, the RKN resistance reactions of the 240 progeny in the two tests, as measured by number of EM observed on the harvested root system, were not significantly different (alpha $=0.05)$. Frequency histograms of the distribution of resistance in the mapping population demonstrated significant skewing toward the resistant parental mean (Fig. 1), suggesting that resistance is quantitative but probably conferred by a few major genes. Transgressive segregation was observed [i.e., a few progeny $(\approx 6 \%)$ exhibiting lower or higher levels of RKN resistance than either parent]. Broad-sense heritability was estimated at $89 \%$.

Single-trait analysis as well as interval mapping and multiple trait analysis revealed the existence of seven chromosomal regions significantly associated with resistance to RKN in 'Tanzania' and two significant regions in 'Beauregard'. Significant regions observed in the 'Tanzania' map explained most of the variation of RKN resistance in the progeny, suggesting that the resistance in the progeny was likely derived from 'Tanzania'. The seven QTL observed in 'Tanzania' corresponded to seven single-dose markers: e32m4920 $(P<0.05$, $\mathrm{LR}=10.8)$, e42m6022 $(P<0.0001, \mathrm{LR}=16.1)$, e46m3201 $(P<$

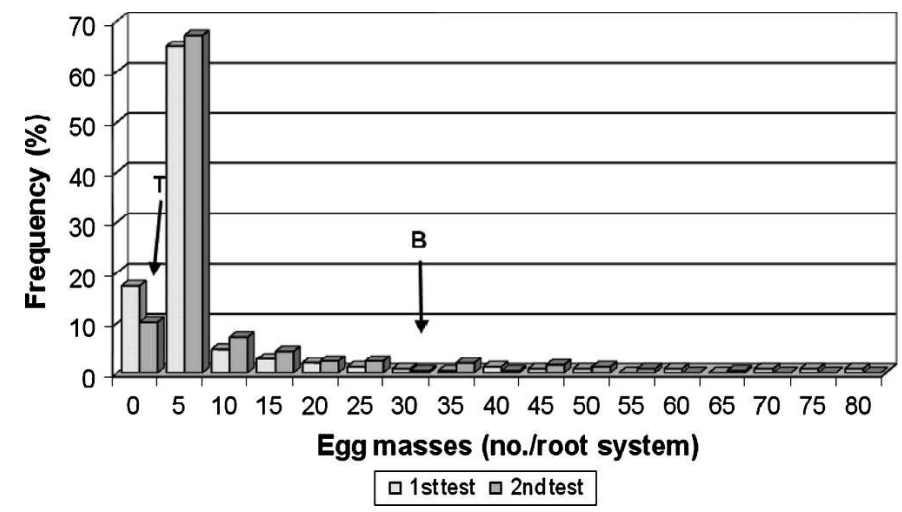

Fig. 1. Histogram of the distribution of the resistance reactions of the progeny from a cross of 'Tanzania' $(T) \times$ 'Beauregard' $(B)$ sweetpotato in terms of the number of egg masses of root-knot nematode per root system.
$0.05, \mathrm{LR}=11)$, e $35 \mathrm{~m} 4414(P<0.01, \mathrm{LR}=12.5)$, e $32 \mathrm{~m} 3722$ $(P<0.0001 ; \mathrm{LR}=14.59)$, e $38 \mathrm{~m} 4512(P<0.0001, \mathrm{LR}=28.9)$, and e36m3811 $(P<0.005, \mathrm{LR}=12.7)$ (Table 1$)$ located on linkage groups T01.01, T05.26, T07.37, T07.38, T07.39, T07.41 and T08.46, respectively (Fig. 2A-B). The QTL localized to linkage groups T05.26, T07.38, T07.41, and T08.46 were negatively correlated with the number of EM present in the root system; therefore, the presence of the marker is associated with a lower number of EM or higher levels of resistance. In contrast, QTL located on linkage group T01.01, T07.37, and T07.39 were positively correlated to the number of egg masses; thus, the presence of the markers is associated with higher number of EM or lower levels of resistance. In 'Beauregard', two regions were associated with RKN resistance corresponding to markers E40M6008 $(P=0.0012, \mathrm{LR}=$ 13) and $\mathrm{E} 42 \mathrm{M} 3525(P=0.0219, \mathrm{LR}=6.7)$ located in linkage groups B04.24 and B07.39, respectively (Fig. 2C). These two regions were negatively correlated with the number of EM; thus, their presence was associated with higher levels of RKN resistance, and both QTL combined accounted for $\approx 6 \%$ of the observed variation in the number of EM.

The significant QTL identified were further analyzed for interactions between QTL and with all other markers in the data set. Significant interactions were observed between QTL and individual markers in 'Tanzania' but not in 'Beauregard'. In 'Tanzania', when the three markers reducing RKN (E32M4920, T01.01; E46M3201, T07.37; and E32M3722, T07.39) resistance were analyzed together, the regression model explained roughly $20 \%$ of the variation in the number of EM (Table 2). When the interaction between E32M4920 (T01.01) and E32M3722 (T07.39) was included in the regression model, the model explained $23 \%$ of the variation. Similarly, when the four significant markers associated with increased resistance to RKN (E42M6022, T05.26; E35M4414, T07.38; E38M4512, T07.41; and E36M3811, T08.46) were analyzed together, the model explained $21 \%$ of the variation, and when significant interactions between markers were

Table 1. Association of AFLP markers with QTL $^{\mathrm{z}}$ for root-knot nematode (RKN) resistance in sweetpotato revealed by singlepoint analysis.

\begin{tabular}{lcccr}
\hline $\begin{array}{l}\text { AFLP } \\
\text { marker }\end{array}$ & $\begin{array}{c}\text { Linkage } \\
\text { group }^{\mathrm{y}}\end{array}$ & $R^{2}$ & $\begin{array}{c}\text { Type of correlation } \\
\text { with EM }\end{array}$ & $P$ value \\
\hline E32M4920 & T01.01 & 0.03728 & +0.16 & 0.0030 \\
E42M6022 & T05.26 & 0.04004 & -0.16 & 0.0021 \\
E46M3201 & T07.37 & 0.04422 & +0.20 & 0.0012 \\
E35M4414 & T07.38 & 0.03722 & -0.18 & 0.0093 \\
E32M3722 & T07.39 & 0.11460 & +0.32 & $<0.0001$ \\
E38M4512 & T07.41 & 0.09089 & -0.30 & $<0.0001$ \\
E36M3811 & T08.46 & 0.05430 & -0.21 & 0.0003 \\
E40M6008 & B04.24 & 0.04492 & -0.20 & 0.0012 \\
E42M3525 & B07.39 & 0.02243 & -0.17 & 0.0219
\end{tabular}

${ }^{\mathrm{z}}$ All observed QTL associated with markers as revealed by PROC GLM in SAS (version 9.1; SAS Institute, Cary, NC).

${ }^{y}$ Linkage groups containing markers associated with RKN resistance: $\mathrm{T}$ indicates that the group is from the 'Tanzania' map and $\mathrm{B}$ indicates that the group is from the 'Beauregard' map.

xAccording to the correlation given by PROC CORR using SAS (Version 9.1), in which EM is the number of egg masses.

AFLP = amplified fragment length polymorphism; $\mathrm{QTL}=$ quantitative trait loci. 
A

T05.26

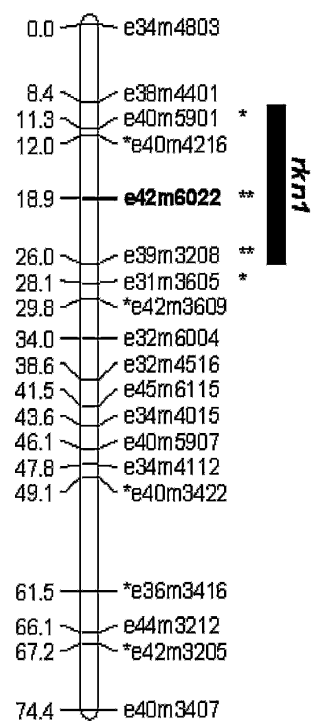

B

T01.01

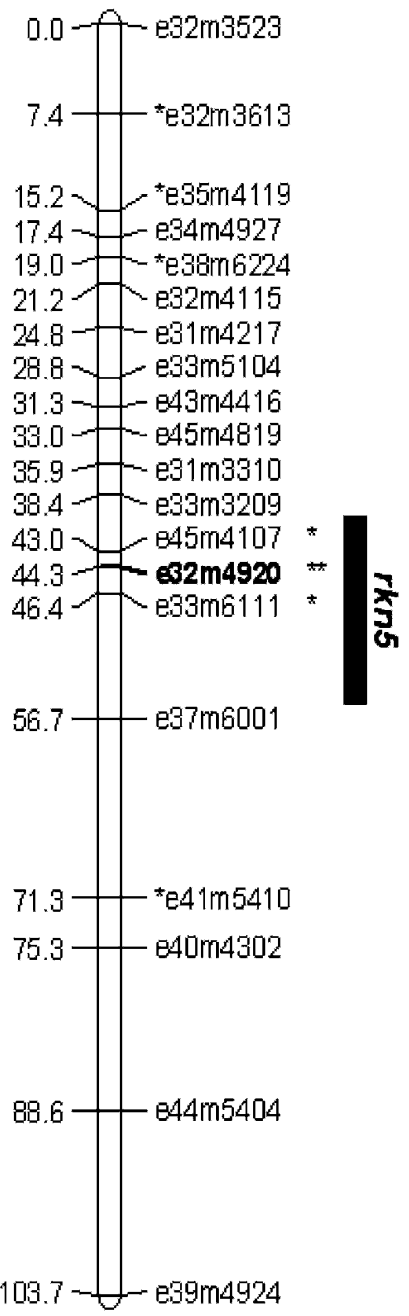

T07.41

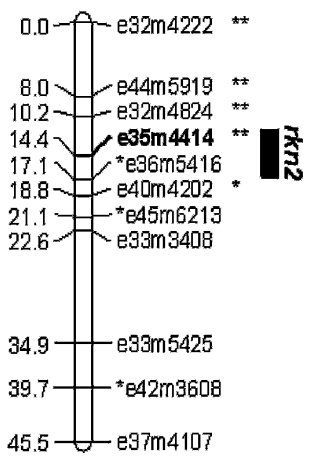

T07.37

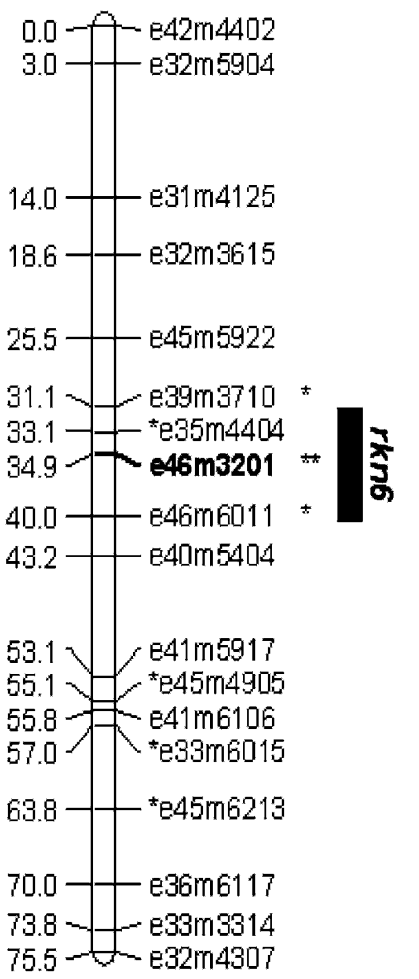

Fig. 2. (Continued on next page)
T08.46



T07.39




accounted for, the model explained $25 \%$ of the variation. When all seven markers were analyzed in a single regression model, the model explained $30 \%$ of the observed variation, and after fitting for marker interactions, the model accounted for $40 \%$ of the variation in EM (Table 2).

In addition to AFLP markers placed on the 'Tanzania' and 'Beauregard' linkage maps, we also conducted QTL analyses using all scored AFLP markers used during the construction of the framework map, some of which were not placed on the linkage map as a result of lack of an adequate recombination of these markers with the mapped markers (Cervantes-Flores et al., 2008). The analyses of the unlinked markers revealed the presence of three duplex AFLP markers (E36M3708, E40M3720, and E42M4202) with very significant $(P<$ 0.0001 ) effects on the variation of RKN resistance. Each of these markers explained between $33 \%$ and $40 \%$ of the observed variation in RKN EM (data not shown). However, we were not

C

B04.24

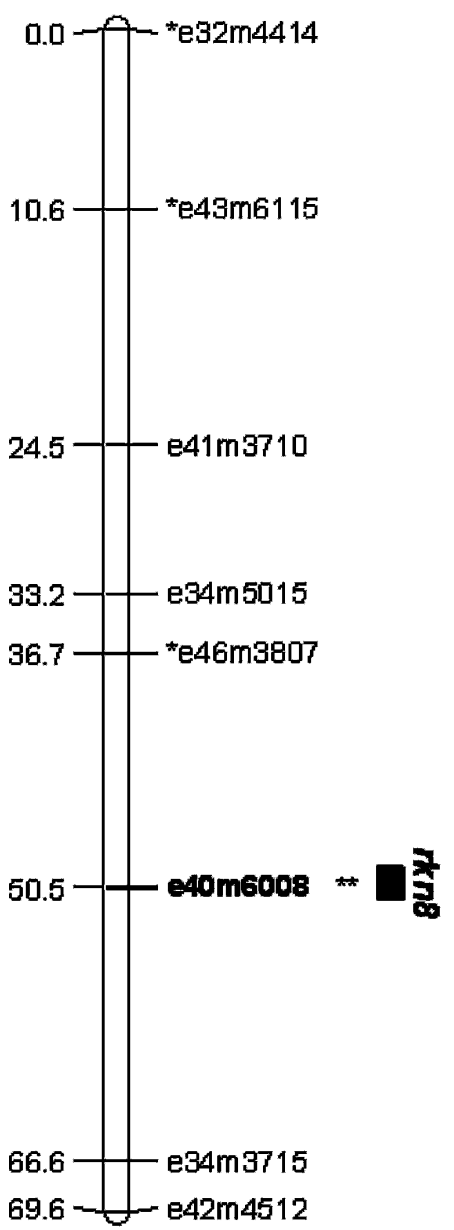

B07.39
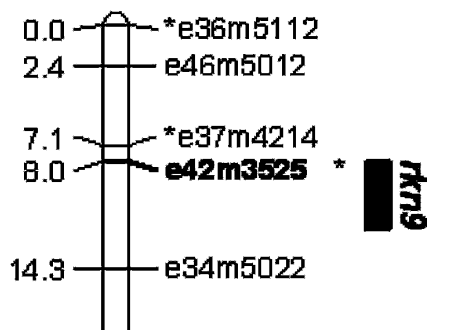

19.7
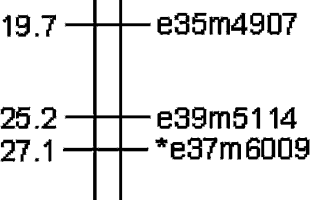

63.8

e32m5015

Fig. 2. Linkage groups containing quantitative trait loci (QTL) associated with root-knot nematode $(\mathrm{RKN})$ resistance in sweetpotato. QTL regions with significant effects as determined by composite interval mapping analysis (1LOD confidence intervals) are shown by the vertical bars. Significance at $5 \%$, $1 \%, 0.1 \%$, and $0.01 \%$ are indicated by $*, * *, * * *$, and $* * * *$, respectively. The markers more significantly associated with the trait, according to analysis of variance analysis, are shown in bold. (A and B) 'Tanzania' linkage groups containing QTL associated with an increase and a reduction in RKN resistance, respectively. (C) 'Beauregard' linkage groups containing QTL associated with an increase in RKN resistance. able to place these markers into the framework map, and thus, the potential QTL could not be located in the 'Tanzania' map; therefore, we could not use these markers because they gave no information regarding the location of QTL associated with resistance to RKN in sweetpotato.

Interval analyses and composite interval analysis confirmed our observations derived from single-point analysis, because the results were not significantly different (data not shown). QTL confidence intervals (1-LOD) calculated by composite interval mapping analysis were used to graphically represent significant QTL in the map.

\section{Discussion}

The mapping population used in this research was better suited for studying resistance to RKN for several reasons. First, previous screening studies on several sweetpotato genotypes to test for resistance to RKN (Cervantes-Flores et al., 2002a, $2002 \mathrm{~b}$ ) revealed the high level of resistance of 'Tanzania' to multiple species and races of nematodes. These same studies demonstrated that 'Beauregard', the main sweetpotato cultivar in United States, was highly susceptible to the same RKN (Cervantes-Flores et al., 2002b). Second, this large mapping population was used to develop the most complete molecular linkage map in sweetpotato to date (Cervantes-Flores et al., 2008); thus, this saturated map could be used for QTL detection.

If the individual data points were considered as a qualitative measurement of resistance (i.e., resistant or susceptible based on EM counts and assignment of clones to resistant and susceptible categories as is commonly done in a breeding program), then the segregation ratio of resistance to RKN would conform to a $4: 1$ ratio (resistant:susceptible). This ratio could be explained by the presence of a double-dose gene, assuming hexasomic inheritance, or by at least two major genes most likely segregating independently. However, the variation of the resistance reaction is quantitative in which a continuum of resistance and susceptibility reactions are observed. Thus, this tendency could be explained by the action of multiple genes with different levels of effect.

The frequency distribution of EM numbers observed on the root masses of the individual clones (Fig. 1) suggest the action of multiple genes with different degrees of effects rather than the effect of two or few genes (Allard, 1999; Young, 1996). Polygenic resistance to pathogens is common in plants, and in studies of resistance to nematodes, multiple genes have been clearly identified and in some cases cloned \{e.g., tomato [Yaghoobi et al., 2005]; potato [Solanum tuberosum L.] [Bryan et al., 2002; Gebhardt et al., 1993]; soybean [Glycine max (L.) Merr.] [Cregan et al., 1999]\}. Similar results have been reported for resistance to other pathogens $\{$ e.g., resistance to Phytophthora infestans [Mont.] de Bary in potato [Meyer et al., 1998], resistance to Cercospora beticola Sacc. in sugar beet [Beta vulgaris L.] [Setiawan et al., 2000], and resistance to blast [Magnaporthe grisea (Hebert) Barr in rice [Oryza sativa L.] [Wang et al., 1994]\}.

The heritability of resistance to $\mathrm{RKN}$ is high $\left(\mathrm{H}_{\text {Broad-sense }}=\right.$ $89 \%$ ) considering that four out of five of the progeny would be considered resistant according to the number of EM present in the root system. In this study, we identified chromosomal regions affecting RKN resistance in both the resistant ('Tanzania') and the susceptible ('Beauregard') parents. In 'Beauregard', there were two QTL with significant effects on the 
Table 2. Estimated $\mathrm{QTL}^{\mathrm{z}}$ effect and significance on the variation of root-knot nematode (RKN) resistance observed in the mapping population for the QTL observed in 'Tanzania' sweetpotato.

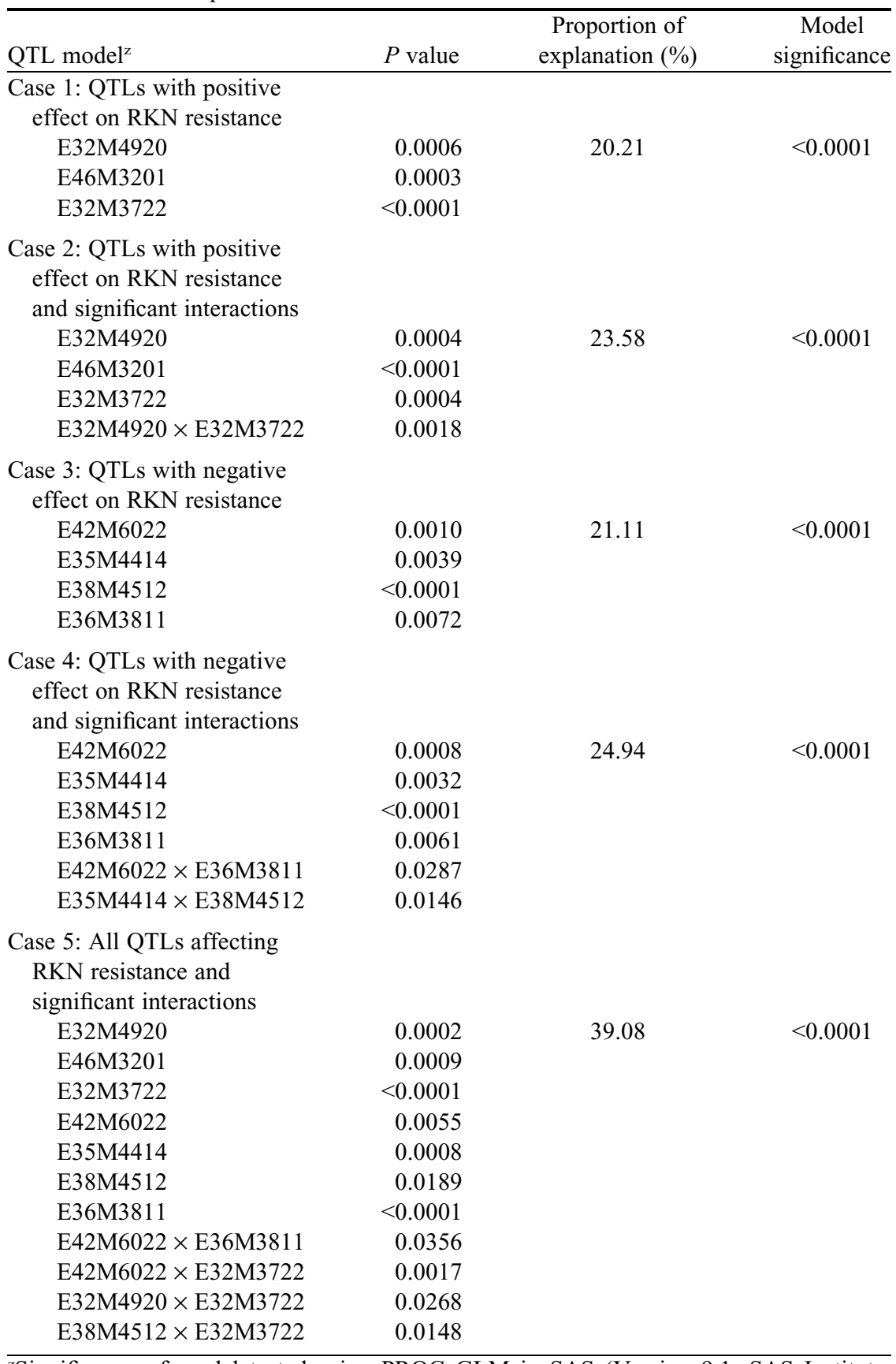

${ }^{\mathrm{z}}$ Significance of model tested using PROC GLM in SAS (Version 9.1; SAS Institute, Cary, NC).

$\mathrm{QTL}=$ quantitative trait loci.

variation to RKN resistance that increased resistance and combined explain $\approx 6 \%$ of this variation. In 'Tanzania', seven QTL had significant effects on the variation of RKN resistance, of which three of the QTL had negative effects on resistance and four of them had positive effects, and when all the markers were included in a regression model, these markers explained $\approx 40 \%$ of the variation in EM observed. These results suggest that in sweetpotato, there are likely to be several different genes acting to contribute to RKN resistance and that additive effects are the most important contributor to RKN resistance in this population. In some instances, the presence of a gene product will enhance resistance, and in other cases, the absence of a gene product will enhance resistance. At this point, we are unable to determine what those elements are and which genes are contributing toward the resistance to RKN in sweetpotato.

Interestingly, no single mapped QTL was found that explained more than $15 \%$ of the variation, implying that the effect of individual QTL is low but their heritability high given the observed ratio of resistant to susceptible progeny (4:1). Also, we observed a transgressive response for RKN resistance, because some clones were seen to be more susceptible than the susceptible parent. In this particular case, some loss of certain favorable alleles in the progeny may be responsible or the accumulation of certain unfavorable alleles that by complementation with other unfavorable ones could produce such a response. Transgressive segregation is well reported in other species for polygenic traits [e.g., plant height, number of internodes, and other fruit traits in tomato (Tanksley, 1993; Young, 1996)].

However, when we considered any of the three unmapped duplex markers from the 'Tanzania' map that showed a very high association with an increased RKN resistance, the explanation of resistance is as high as $45 \%$ (data not shown). This may indicate that these markers may be potentially associated with a gene or genes with major effects present in a double dose. This would then explain most of the variation in resistance against RKN. If this proves to be the case, it would imply that the number of copies of the resistance genes is an important factor for providing protection to the plant against nematodes, and this would agree with the observed segregation ratio for resistance when it is considered as a qualitative trait. Nevertheless, to prove such a hypothesis, further analysis is needed, specifically through the addition of more markers onto the map. Also, these unmapped markers could be converted to simplex markers and incorporated into the map to test them for an association with the trait and/or to detect if they colocalize within an already detected QTL. Another approach would be to further analyze these regions through a genomic library and subsequent sequencing to determine the presence of resistance gene analogs.

In conclusion, this research presents the most detailed QTL analyses conducted to associate RKN resistance loci with molecular markers in sweetpotato to date. We have identified seven QTL regions of importance in the 'Tanzania' map and two regions in the 'Beauregard' map. Additionally, we have identified three currently unmapped duplex markers with highly significant effects on RKN resistance. Further research 
will be conducted to validate our QTL, develop simplex polymerase chain reaction fragments, and clone these regions to determine what specific genes are responsible for these QTL. Comparison with other RKN resistance genes already sequenced from other plant species could also help identify the nature of resistance and thereby increase our understanding of the source of resistance to RKN in sweetpotato. Based on our observations, RKN resistance may be an amenable trait for marker-assisted selection once the QTL have been validated in unrelated germplasm, and their efficiency in predicting desirable genotypes has been assessed. This work is the first step for mapping RKN resistance genes in sweetpotato using a saturated genetic linkage map. Nevertheless, much work is needed before the desired genes can be completely identified and used for marker-assisted selection in sweetpotato. This work is one aspect of a larger effort focused on the development of genetic tools for the application of biotechnology and genomics for sweetpotato breeding.

\section{Literature Cited}

Allard, R.W. 1999. Principles of plant breeding. Wiley, New York, NY.

Barr, A.R., K.J. Chalmers, A. Karakousis, J.M. Kretschmer, S. Manning, R.C.M. Lance, J. Lewis, S.P. Jeffries, and P. Langridge. 1998. RFLP mapping of a new cereal cyst nematode resistance locus in barley. Plant Breed. 117:185-187.

Bryan, G., K. McLean, J.E. Bradshaw, W.S. De Jong, M. Phillips, L. Castelli, and R. Waugh. 2002. Mapping QTLs for resistance to the cyst nematode Globodera pallida derived from the wild potato species Solanum vernei. Theor. Appl. Genet. 105:6877.

Cervantes-Flores, J.C., G.C. Yencho, and E.L. Davis. 2002a. Efficient evaluation of resistance to three root-knot nematode species in selected sweetpotato cultivars. HortScience 37:390-392.

Cervantes-Flores, J.C., G.C. Yencho, and E.L. Davis. 2002b. Host reactions of sweetpotato genotypes to root-knot nematodes and variation in virulence of Meloidogyne incognita populations. HortScience 37:1112-1116.

Cervantes-Flores, J.C., G.C. Yencho, A. Kriegner, P. Pecota, M.A. Faulk, R.O.M. Mwanga, and B. Sosinski. 2008. Development of a genetic map and identification of homologous linkage groups in sweetpotato using multiple-dose AFLP markers. Mol. Breed. 21:511-532.

Clark, C. and J.W. Moyer. 1988. Compendium of sweet potato diseases. APS Press, St. Paul, MN.

Collard, B.C.Y., M.Z.Z. Jahufer, J.B. Brouwer, and E.C.K. Pang. 2005. An introduction to markers, quantitative trait loci (QTL) mapping and marker-assisted selection for crop improvement: The basic concepts. Euphytica 142:169-196.

Cordner, H.B., F.B. Struble, and L. Morrison. 1954. Breeding sweetpotatoes for resistance to the root-knot nematode. Plant Dis. Rptr. Suppl. 227:92-93.

Cregan, P.B., J. Mudge, E.W. Fickus, D. Danesh, R. Denny, and N.D. Young. 1999. Two simple sequence repeat markers to select for soybean cyst nematode resistance conditioned by the rhgl locus. Theor. Appl. Genet. 99:811-818.

Dirlewanger, E., P.G. Isaac, S. Ranade, M. Belajouza, R. Cousin, and D. de Vienne. 1994. Restriction fragment length polymorphism analysis of loci associated with disease resistance genes and developmental traits in Pisum sativum L. Theor. Appl. Genet. 88:1727.

Doerge, R.W., Z.B. Zeng, and B.S. Weir. 1997. Statistical issues in the search for genes affecting quantitative traits in experimental populations. Stat. Sci. 12:195-219.

Dropkin, V.H. 1969a. Cellular responses of plants to nematode infections. Annu. Rev. Phytopathol. 7:101-122.
Dropkin, V.H. 1969b. The necrotic reaction of tomatoes and other host resistants to Meloidogyne: Reversal by temperature. Phytopathology 59:1632-1637.

Gebhardt, C., D. Mugniery, E. Ritter, F. Salamini, and E. Bonnel. 1993. Identification of RFLP markers closely linked to the $H 1$ gene conferring resistance to Globodera rostochiensis in potato. Theor. Appl. Genet. 85:541-544.

Gebhardt, C. and J.P.T. Valkonen. 2001. Organization of genes controlling disease resistance in the potato genome. Annu. Rev. Phytopathol. 39:79-102.

Giamalva, M., T. Hernandez, W. Martin, and J. Miller. 1961. Testing sweetpotato progenies for nematode resistance. Proc. Ann. Conv. Assn. Southern Agr. Workers 58:174.

Hussey, R. and K. Barker. 1973. A comparison of methods of collecting inocula of Meloidogyne spp., including a new technique. Plant Dis. Rptr. Suppl. 57:1025-1028.

Jatala, P. 1991. Biology and management of plant parasitic nematodes on sweetpotato, p. 359-378. In: Janson, R. and K.V. Raman (eds.). Sweetpotato pest management. Westview Press, Boulder, CO. Jones, A. and P.D. Dukes. 1980. Heritabilities of sweetpotato resistances to root-knot caused by Meloidogyne incognita and $M$. javanica. J. Amer. Soc. Hort. Sci. 105:154-156.

Komiyama, A., Z.I. Sano, T. Murata, Y. Matsuda, M. Yoshida, A. Saito, and Y. Okada. 2006. Resistance to two races of Meloidogyne incognita and resistance mechanism in diploid Ipomoea trifida. Breed. Sci. 56:81-83.

Lagudah, E.S., O. Moullet, and R. Appels. 1997. Map-based cloning of a gene sequence encoding a nucleotide binding domain and a leucine-rich region at the $\mathrm{Cre} 3$ nematode resistance locus of wheat. Genome 40:659-665.

Lander, E.S. and D. Botstein. 1989. Mapping mendelian factors underlying qualitative traits using RFLP linkage maps. Genetics 121:185-199.

Lawrence, G.W., C.A. Clark, and V.L. Wright. 1986. Influence of Meloidogyne incognita on resistant and susceptible sweetpotato cultivars. J. Nematol. 18:59-65.

Mcharo, M., D. LaBonte, R.O.M. Mwanga, and A. Kriegner. 2005a. Associating molecular markers with virus resistance to classify sweetpotato genotypes. J. Amer. Soc. Hort. Sci. 130:355-359.

Mcharo, M., D.R. LaBonte, C. Clark, M. Hoy, and J.H. Oard. 2005 b. Molecular marker variability for southern root-knot nematode resistance in sweetpotato. Euphytica 144:125-132.

Meyer, R.C., D. Milbourne, C.A. Hackett, J.E. Bradshaw, J.W. McNichol, and R. Waugh. 1998. Linkage analysis in tetraploid potato and association of markers with quantitative resistance to late blight. Mol. Gen. Genet. 259:150-160.

Nyquist, W.E. 1991. Estimation of heritability and prediction of selection response in plant population. Crit. Rev. Plant Sci. 10:235-322.

Mwanga, R.O.M., A. Kriegner, J.C. Cervantes-Flores, D.P. Zhang, J.W. Moyer, and G.C. Yencho. 2002. Resistance to sweetpotato chlorotic stunt virus and sweetpotato feathery mottle virus is mediated by two separate recessive genes in sweetpotato. J. Amer. Soc. Hort. Sci. 127:798-806.

Paulson, R.E. and J.M. Webster. 1972. Ultrastructure of hypersensitive reaction in roots of tomato, Lycopersicon esculentum L., to infection by root-knot nematode, Meloidogyne incognita. Physiol. Plant Pathol. 2:227-234.

Ripol, M.I., G.A. Churchill, J.A. da Silva, and M.E. Sorrells. 1999. Statistical aspects of genetic mapping in autopolyploids. Gene 235:31-41.

Sano, Z.I., H. Iwahori, Y. Tateishi, and Y. Kai. 2002. Differences in the resistance of sweetpotato cultivars and lines to Meloidogyne incognita populations. Jpn. J. Nematol. 32:77-86.

Sasser, J.N. 1980. Root-knot nematodes: A global menace to crop production. Plant Dis. 64:36-41.

Sasser, J.N. and C.C. Carter. 1985. Overview of the international Meloidogyne project $1975-84$, p. 19-24. In: Sasser, J.N. and C.C. 
Carter (eds.). An advanced treatise on Meloidogyne: Biology and control. NCSU Graphics, Raleigh, NC.

Setiawan, A., G. Koch, D.R. Barnes, and C. Jung. 2000. Mapping quantitative trait loci (QTLs) for resistance to Cercospora leaf spot disease (Cercospora beticola Sacc.) in sugar beet (Beta vulgaris L.). Theor. Appl. Genet. 100:1176-1182.

Struble, F.B., L.S. Morrison, and H.B. Cordner. 1966. Inheritance of resistance to stem rot and to root knot nematode in sweetpotato. Phytopathology 56:1217-1219.

Tanksley, S.D. 1993. Mapping polygenes. Annu. Rev. Genet. 27:205233.

Tao, W., D. Liu, J. Liu, Y. Feng, and P. Chen. 2000. Genetic mapping of the powdery mildew resistance gene Pm6 in wheat by RFLP analysis. Theor. Appl. Genet. 100:564-568.

Taylor, A.L., J.N. Sasser, and L.A. Nelson. 1982. Relationship of climate and soil characteristics to geographical distribution of Meloidogyne species in agricultural soils. Intl. Meloidogyne Project, Raleigh, NC.

Thomas, R.J. and C. Clark. 1983. Population dynamics of Meloidogyne incognita and Rotylenchus reniformis alone and in combination, and their effects on sweetpotato. J. Nematol. 15:204-211.

Ukoskit, K., P.G. Thompson, C.E. Watson, and G.W. Lawrence. 1997. Identifying a randomly amplified polymorphic DNA (RAPD) marker linked to a gene for root-knot nematode resistance in sweetpotato. J. Amer. Soc. Hort. Sci. 122:818-821.

Voorrips, R.E. 2002. MapChart: Software for graphical presentation of linkage groups and QTLs. J. Hered. 93:77-78.

Wang, D., P.R. Arelli, R.C. Shoemaker, and B.W. Diers. 2001. Loci underlying resistance to race 3 of soybean cyst nematode in Glycine soja plant introduction 468916. Theor. Appl. Genet. 103: 561-566.

Wang, G.L., D.J. Mackill, M. Bonman, S.R. McCouch, M.C. Champoux, and R.J. Nelson. 1994. RFLP mapping of genes conferring complete and partial resistance to blast in a durably resistant rice cultivar. Genetics 136:1421-1434.

Wang, S., C.J. Basten, P. Gaffney, and Z.B. Zeng. 2005. Windows QTL Cartographer 2.5. 3 Oct. 2008. <http://statgen.ncsu.edu/qtlcart/ WQTLCart.htm>.

Whitehead, A.G. 1998. Plant nematode control. CAB International, Wallingford, UK.

Yaghoobi, J., J.L. Yates, and V.M. Williamson. 2005. Fine mapping of the nematode resistance gene Mi-3 in Solanum peruvianum and construction of a $S$. lycopersicum DNA contig spanning the locus. Mol. Gen. Genet. 274:60-69.

Young, N.D. 1996. QTL mapping and quantitative disease resistance in plants. Annu. Rev. Phytopathol. 34:479-501. 